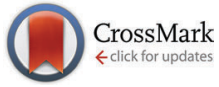

Cite this: Chem. Commun., 2014, 50, 10883

Received 19th May 2014,

Accepted 29th July 2014

DOI: $10.1039 / \mathrm{c} 4 \mathrm{cc} 03806 a$

www.rsc.org/chemcomm

\section{Electronic coupling mediated by furan, thiophene, selenophene and tellurophene in a homologous series of organic mixed valence compounds $\dagger$}

\author{
Ann Christin Jahnke, Mariana Spulber, Markus Neuburger, Cornelia G. Palivan and \\ Oliver S. Wenger*
}

\begin{abstract}
Charge delocalization in the mixed-valent monocationic forms of phenothiazine-decorated chalcogenophenes is explored by cyclic voltammetry, optical absorption and EPR spectroscopy. Single units of furan, thiophene, selenophene and tellurophene are found to mediate electronic coupling between the phenothiazines attached to their 2- and 5-positions roughly equally well. Electronic communication seems to occur mostly through the butadiene-like backbone of the chalcogenophenes.
\end{abstract}

The ability of $\pi$-conjugated oligomers and polymers to become highly conducting upon oxidation is of key importance for various (opto)electronic applications. ${ }^{1}$ Numerous studies have investigated charge delocalization and charge transport phenomena in oxidized oligo- and polythiophenes. ${ }^{2}$ Lately there has been increasing interest in oligomers and polymers of the other chalcogenophenes, in particular selenophene, ${ }^{3}$ but also furan and tellurophene. ${ }^{4}$ However, despite important recent progress, the synthesis of oligofurans and oligotellurophenes remains nontrivial. ${ }^{5}$ From a fundamental perspective and with the application potential of furan- or tellurophene-based materials in mind, it seemed worthwhile to explore to what extent an unpaired electron can delocalize over individual chalcogenophene units with the heteroatoms varying along the series $\mathrm{O}, \mathrm{S}, \mathrm{Se}, \mathrm{Te}$. Charge transport in oligomers and charge delocalization in monomers are different issues, but in order to tailor the properties of an oligomer or polymer it seems desirable to understand the electronic structure of its monomeric building blocks as detailed as possible.

Mixed valence compounds have been frequently employed for exploration of charge delocalization phenomena, and both metalbased as well as purely organic redox-active units have been used for this purpose. ${ }^{6}$ A considerable number of thiophene-bridged mixed valence compounds have been studied, ${ }^{7}$ but selenophene, furan,

Department of Chemistry, University of Basel, St. Johanns-Ring 19, CH-4056 Basel, Switzerland. E-mail: oliver.wenger@unibas.ch

$\dagger$ Electronic supplementary information (ESI) available: Synthesis protocols and product characterization data, additional optical spectroscopic and EPR data. CCDC 1002373. For ESI and crystallographic data in CIF or other electronic format see DOI: 10.1039/c4cc03806a

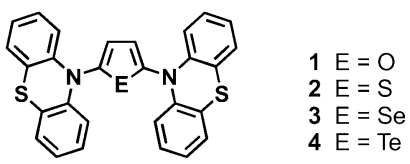

Scheme 1 Molecular structure of the systems investigated in this study.

and tellurophene bridges have received little to no attention. ${ }^{7 k, 8}$ A very recent study reported that oligofurans can mediate stronger electronic coupling between ferrocenyl redox units than oligothiophenes. ${ }^{8 a}$ We are unaware of prior comparative studies of charge delocalization encompassing the entire chalcogenophene series (Scheme 1).

Our study is based on four isostructural compounds with phenothiazine (PTZ) groups attached at the 2- and 5-positions of furan (1), thiophene (2), selenophene (3), and tellurophene (4). An X-ray crystal structure of the selenophene compound is shown in Fig. 1. The structure of the thiophene analogue (2) had been previously reported. ${ }^{7 m}$ Synthetic procedures and product characterization data are given in the ESI. $\dagger$

Cyclic voltammetry reveals two essentially reversible oxidation waves in the potential range between 0 and $0.6 \mathrm{~V} v s . \mathrm{Fc}^{+} / \mathrm{Fc}$ for all four compounds (Fig. 2), corresponding to consecutive one-electron oxidation of both PTZ moieties. Chalcogenophene-based oxidations are expected at much higher potentials. ${ }^{9}$ In $\mathrm{CH}_{3} \mathrm{CN}$ with $0.1 \mathrm{M}$ $\mathrm{TBAPF}_{6}$ the splitting between peak potentials $(\Delta E)$ increases along the chalcogenophene series, ranging from $216 \mathrm{mV}$ for furan to

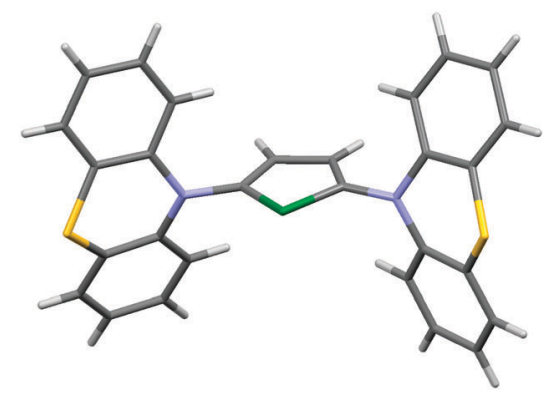

Fig. 1 X-ray crystal structure of compound 3. 


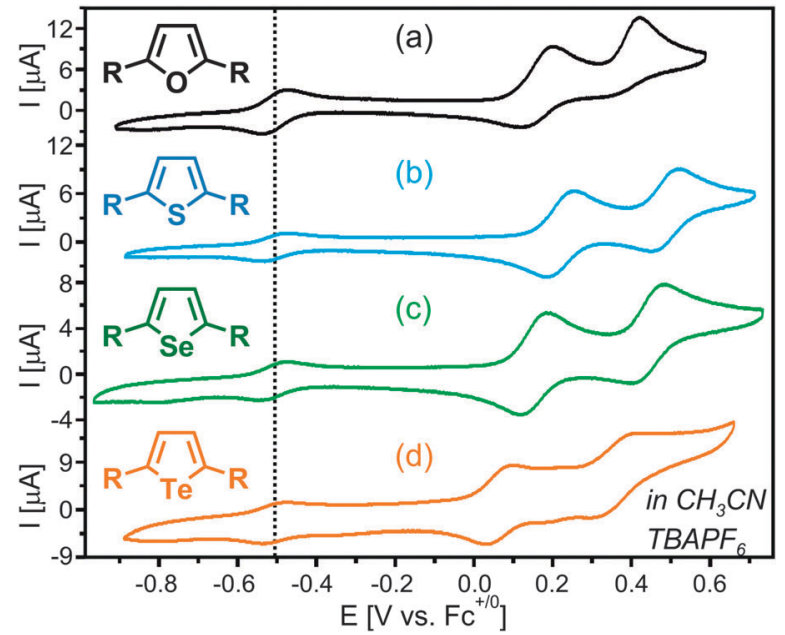

Fig. 2 Cyclic voltammograms recorded in $\mathrm{CH}_{3} \mathrm{CN}$ with $0.1 \mathrm{MTBAPF}$. The scan rate was $100 \mathrm{mV} \mathrm{s}^{-1}$.

Table 1 Differences in electrochemical potentials for one-electron oxidation of the two PTZ units and comproportionation constants in $\mathrm{CH}_{3} \mathrm{CN}$ with $0.1 \mathrm{M} \mathrm{TBAPF}_{6}$

\begin{tabular}{lll}
\hline Compd & $\Delta E[\mathrm{mV}]$ & $K_{\mathrm{c}}$ \\
\hline $\mathbf{1}$ & 216 & $4.5 \times 10^{3}$ \\
$\mathbf{2}$ & 267 & $3.4 \times 10^{4}$ \\
$\mathbf{3}$ & 283 & $6.3 \times 10^{4}$ \\
$\mathbf{4}$ & 291 & $8.6 \times 10^{4}$
\end{tabular}

$291 \mathrm{mV}$ for tellurophene (Table 1). Using these $\Delta E$ values one calculates comproportionation constants $\left(K_{\mathrm{c}}=10^{\Delta E / 59 \mathrm{mV}}\right)$ between $4.5 \times 10^{3}$ and $8.6 \times 10^{4}$ in $\mathrm{CH}_{3} \mathrm{CN}$ (Table 1). In general, $\Delta E$ and $K_{\mathrm{c}}$ are governed by several factors including electrostatic and ion pairing effects, as well as the strength of electronic interaction $\left(H_{\mathrm{AB}}\right)$ between the two redox centers. ${ }^{10}$ Electrostatic and ion pairing effects often dominate, and therefore conclusions about $H_{\mathrm{AB}}$ based on electrochemical data should be made with caution. ${ }^{8 b}$ In the present case the observed increase of $\Delta E$ and $K_{\mathrm{c}}$ along the series of chalcogenophenes 1-4 is difficult to reconcile with electrostatics because the distance between redox centers is not decreasing along this series.

While $4 \times 10^{-5} \mathrm{M}$ solutions of the charge-neutral forms of 1-4 in $\mathrm{CH}_{3} \mathrm{CN}$ are essentially colorless (dotted black traces in Fig. 3), oxidation with $\mathrm{Cu}\left(\mathrm{ClO}_{4}\right)_{2}$ produces new absorptions in the nearinfrared and visible spectral ranges. In all four cases the lowestenergy absorption band is centered around 14500-15000 $\mathrm{cm}^{-1}$, reaching its maximum intensity after addition of 1 equivalent of $\mathrm{Cu}$ (II) oxidant (red traces, bands marked with asterisks) from which we conclude that these bands are due to the mixed-valent $\mathbf{1}^{+}-\mathbf{4}^{+}$ species. As frequently observed, addition of a second equivalent of $\mathrm{Cu}\left(\mathrm{ClO}_{4}\right)_{2}$ oxidant is unable to quantitatively convert the mono- to the dications. ${ }^{6 f}$ However, the abovementioned low-energy bands clearly lose intensity when more than 1 equivalent of oxidant is added, and for $2^{2+}-4^{2+}$ a new absorption band around $19500 \mathrm{~cm}^{-1}$ becomes detectable (dash-dotted black traces). In the case of molecule 1 addition of a second equivalent of oxidant rapidly leads to sample decomposition.

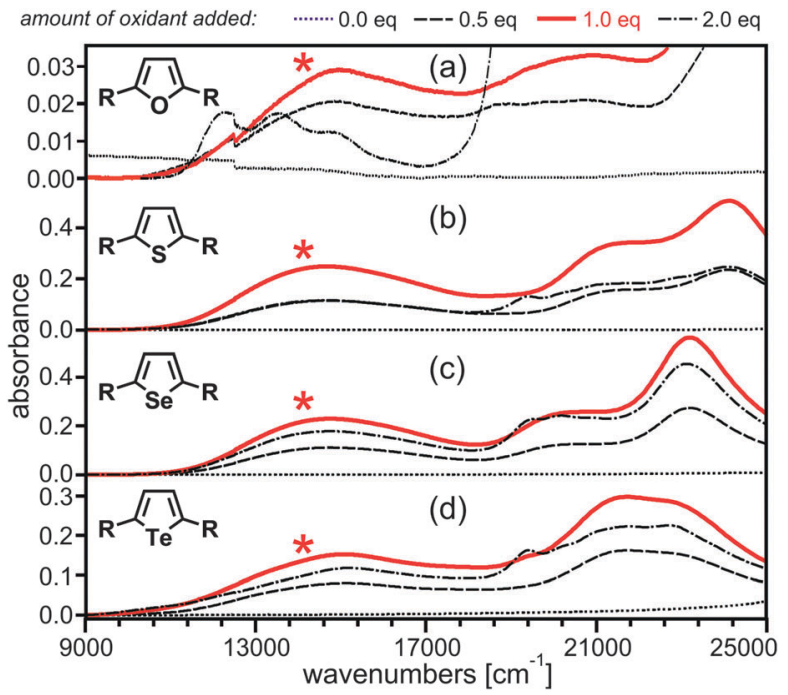

Fig. 3 Absorption spectra recorded in absence and in presence of various amounts of $\mathrm{Cu}\left(\mathrm{ClO}_{4}\right)_{2}$ oxidant in $\mathrm{CH}_{3} \mathrm{CN}$. The asterisks mark the IVCT band.

By analogy to many previously investigated bis(triarylamines) and related organic mixed valence compounds we associate the low-energy absorptions of $\mathbf{1}^{+} \mathbf{4}^{+}$(marked by the red asterisks) with intervalence charge transfer (IVCT) bands. ${ }^{6 b, f, h, 7 g, j, k, p, s, 11}$ The optical absorption spectra with properly determined extinction coefficients were fitted to a sum of Gaussian functions in order to estimate the dipole moment $\left(\mu_{\mathrm{ge}}\right)$ associated with the IVCT transition (Fig. S1 in the ESI $\dagger$ ). Eqn (1) requires $\nu_{\max }$ (the energetic position of the absorption band maximum) and $\varepsilon(\nu)$ input values in units of $\mathrm{cm}^{-1}$ and $\mathbf{M}^{-1} \mathrm{~cm}^{-1}$, respectively, and yields the transition dipole moment in units of Debyes (D). ${ }^{12}$

$$
\mu_{\mathrm{ge}}=0.09584 \cdot \sqrt{\frac{\int \varepsilon(v) \cdot \mathrm{d} v}{v_{\max }}}
$$

The $\mu_{\text {ge }}$ values for the furan-, thiophene-, selenophene-, and tellurophene-based compounds $\left(\mathbf{1}^{+}, 2^{+}, 3^{+}, 4^{+}\right)$are between 3.4 and $4.7 \mathrm{D}$ (Table 2). Eqn (2) relates $\mu_{\mathrm{ge}}$ to the electronic coupling matrix element $H_{\mathrm{AB}}$ which quantifies the strength of the electronic interaction between the two redox centers. ${ }^{13}$

$$
H_{\mathrm{AB}}=\frac{\mu_{\mathrm{ge}} \cdot v_{\max }}{e \cdot R}
$$

In eqn (2), $e$ is the elemental charge and $R$ is the effective charge transfer distance. In compounds 1-4 the N-N distance is expected to vary between 4.58 and $5.32 \AA$ based on molecular modeling and X-ray crystal structure data (Table 1). Prior studies of mixed-valent bis(triarylamine) cations and dinitroaromatic anions have reached the conclusion that $R$ is equal to roughly $2 / 3$ of the geometrical $\mathrm{N}-\mathrm{N}$ distance $\left(d_{\mathrm{NN}}\right)$ in these systems. ${ }^{14}$ Therefore it seems plausible to assume that $R \approx 2 / 3$. $d_{\mathrm{NN}}$ for $\mathbf{1}^{+}-\mathbf{4}^{+}$, and this leads to estimates for the electronic coupling matrix elements in the range from $\sim 3300$ to $\sim 4100 \mathrm{~cm}^{-1}$ (Table 2). For comparison, the structurally related $N, N, N^{\prime}, N^{\prime}$ tetraanisyl- $p$-phenylenediamine cation has $H_{\mathrm{AB}}=3240 \mathrm{~cm}^{-1} \cdot{ }^{11 a}$ The solvent dependence of the IVCT band is relatively weak, 
Table 2 Geometrical N-N distances, energetic positions of IVCT absorption band maxima, dipole moments associated with the IVCT transitions, and electronic coupling matrix elements characterizing the interaction between PTZ redox units

\begin{tabular}{lllll}
\hline Compd & $d_{\mathrm{NN}}[\AA]$ & $\nu_{\max }\left[\mathrm{cm}^{-1}\right]$ & $\mu_{\mathrm{ge}}[\mathrm{D}]$ & $H_{\mathrm{AB}}\left[\mathrm{cm}^{-1}\right]$ \\
\hline $\mathbf{1}^{+}$ & $4.58^{a}$ & 14970 & 3.4 & 3580 \\
$\mathbf{2}^{+}$ & $5.16^{b}$ & 14560 & 4.7 & 4125 \\
$\mathbf{3}^{+}$ & $5.16^{b}$ & 14660 & 4.3 & 3815 \\
$\mathbf{4}^{+}$ & $5.32^{a}$ & 15020 & 3.8 & 3325
\end{tabular}

${ }^{a}$ Determined by molecular modeling. ${ }^{b}$ Determined from X-ray crystal structures. $^{7 m}$

$\nu_{\max }$ red-shifts between $\sim 500$ and $\sim 1500 \mathrm{~cm}^{-1}$ when changing from $\mathrm{CH}_{3} \mathrm{CN}$ to $\mathrm{CH}_{2} \mathrm{Cl}_{2}$ (Fig. S2, ESI $\dagger$ ).

The EPR spectra of $\mathbf{1}^{+}-\mathbf{4}^{+}$in $\mathrm{CH}_{3} \mathrm{CN}$ indicate that the unpaired electron spin interacts with the nuclear spins of ${ }^{14} \mathrm{~N}$ and ${ }^{1} \mathrm{H}$ (solid traces in Fig. 4). Simulation of the experimental spectra (dotted traces in Fig. 4) yields the gyromagnetic factors $g$, and the hyperfine coupling constants reported in Table 3. All EPR spectra are centered at values of the gyromagnetic factors $\mathrm{g}$ ranging from 2.0024 to 2.0032, typical for organic radicals. The simulations indicate an interaction of the unpaired electron with two equivalent nitrogen nuclei $\left(a_{\mathrm{N}}\right.$ ranging from 4.2 to $5.2 \mathrm{G}$ ), and two equivalent hydrogen nuclei $\left(a_{\mathrm{H}}\right.$ varying from 3.6 to $\left.4.8 \mathrm{G}\right)$ for the two chalcogenophene $\mathrm{H}$-atoms. Nitrogen hyperfine coupling constants $\left(a_{\mathrm{N}}\right)$ between 4.2 and $5.2 \mathrm{G}$ for $\mathbf{1}^{+} \mathbf{- 4}^{+}$are compatible with complete delocalization of the unpaired electron over two $\mathrm{N}$ nuclei on the EPR timescale. In the case of $\mathbf{4}^{+}$the presence of an impurity somewhat complicates analysis of the EPR data (see ESI $\dagger$ for details) but reliable parameters can nevertheless be determined. For $\mathbf{1}^{+}-3^{+}$there is no indication for hyperfine interaction with the chalcogenophene heteroatom. For $\mathbf{4}^{+}$interaction of the unpaired electron with the tellurium atom cannot be rigorously excluded (see ESI $\dagger$ ).

The combined data sets from cyclic voltammetry, optical absorption, and EPR spectroscopy are in line with strong charge delocalization in $\mathbf{1}^{+}-\mathbf{4}^{+} . \Delta E$ and $K_{\mathrm{c}}$ increase systematically along the chalcogenophene series (Table 1), but for $\mu_{\mathrm{ge}}$ and $H_{\mathrm{AB}}$ this trend is not followed (Table 2). The optical absorption data
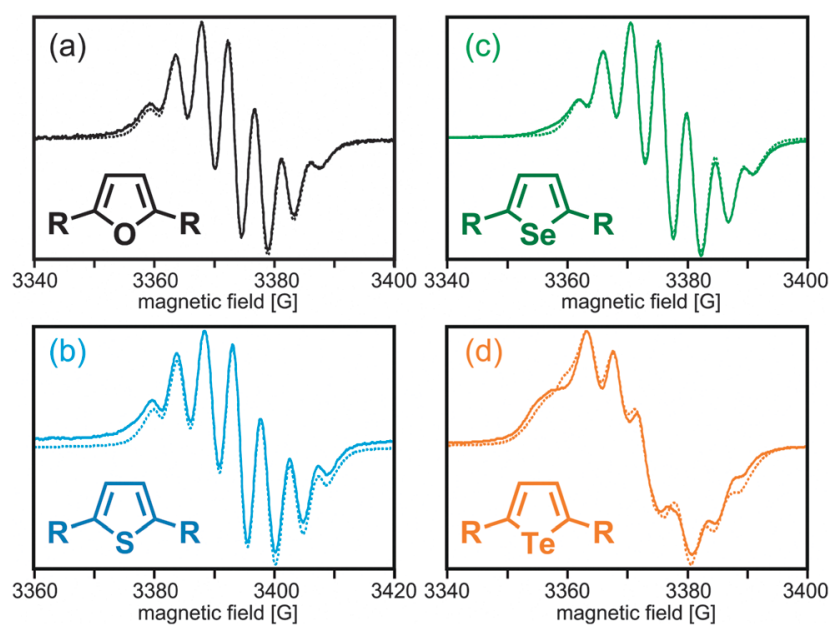

Fig. 4 Solid lines: experimental $X$-band EPR spectra recorded for the monocationic forms in $\mathrm{CH}_{3} \mathrm{CN}$. Dotted lines: simulated spectra. See ESI. $\dagger$
Table 3 EPR gyromagnetic factors and hyperfine coupling constants for compounds $1^{+}-4^{+}$

\begin{tabular}{llll}
\hline Compd & $g$ & $a_{\mathrm{N}}[\mathrm{G}]$ & $a_{\mathrm{H}}[\mathrm{G}]$ \\
\hline $\mathbf{1}^{+}$ & 2.0032 & 4.2 & 4.8 \\
$\mathbf{2}^{+}$ & 2.0032 & 4.8 & 3.9 \\
$\mathbf{3}^{+}$ & 2.0024 & 4.9 & 3.6 \\
$\mathbf{4}^{+}$ & 2.0030 & 5.2 & 4.0
\end{tabular}

rather suggests that furan and tellurophene mediate electronic coupling somewhat less well than thiophene and selenophene, but the differences are relatively small when considering the uncertainty associated with the procedure used for determination of $\mu_{\mathrm{ge}}$ and $H_{\mathrm{AB}}$. We are therefore lead to the conclusion that single units of furan, thiophene, selenophene, and tellurophene mediate electronic coupling between two amine redox centers similarly well. This is consistent with a picture in which the electronic communication between the 2- and 5-positions of a chalcogenophene is mostly mediated by the butadiene backbone of the heterocycle, and the EPR data is compatible with this view. A recent study of ferrocene-based mixed valence compounds has reached the same conclusion for phosphole bridges. ${ }^{15}$

We have conducted the first comparative study of charge delocalization across single units of the entire chalcogenophene series, and our findings are relevant in the greater context of molecular electronics, ${ }^{16}$ for instance for the design of new chalcogenophene-based charge-conducting oligomers and polymers.

Funding from the Swiss NSF through grant number 200021_146231/1 is gratefully acknowledged. CGP acknowledges the Swiss NSF for a R'Equip grant for the EPR spectrometer.

\section{Notes and references}

1 (a) X. Guo, M. Baumgarten and K. Müllen, Prog. Polym. Sci., 2013, 38, 1832-1908; (b) J. L. Brédas, J. P. Calbert, D. A. da Silva and J. Cornil, Proc. Natl. Acad. Sci. U. S. A., 2002, 99, 5804-5809.

2 (a) J. Roncali, Chem. Rev., 1992, 92, 711-738; (b) T. Otsubo, Y. Aso and K. Takimiya, J. Mater. Chem., 2002, 12, 2565-2575.

3 (a) E. Poverenov, Y. Sheynin, N. Zamoshchik, A. Patra, G. Leitus, I. F. Perepichka and M. Bendikov, J. Mater. Chem., 2012, 22, 14645-14655; (b) A. Patra and M. Bendikov, J. Mater. Chem., 2010, 20, 422-433; (c) Y. H. Wijsboom, A. Patra, S. S. Zade, Y. Sheynin, M. Li, L. L. W. Shimon and M. Bendikov, Angew. Chem., Int. Ed., 2009, 48, 5443-5447; (d) M. Heeney, W. Zhang, D. J. Crouch, M. L. Chabinyc, S. Gordeyev, R. Hamilton, S. J. Higgins, I. McCulloch, P. J. Skabara, D. Sparrowe and S. Tierney, Chem. Commun., 2007, 5061-5063.

4 (a) O. Gidron, A. Dadvand, Y. Sheynin, M. Bendikov and D. F. Perepichka, Chem. Commun., 2011, 47, 1976-1978; (b) O. Gidron and M. Bendikov, Angew. Chem., Int. Ed., 2014, 53, 2546-2555; (c) A. A. Jahnke and D. S. Seferos, Macromol. Rapid Commun., 2011, 32, 943-951; (d) A. A. Jahnke, G. W. Howe and D. S. Seferos, Angew. Chem., Int. Ed., 2010, 49, 10140-10144.

5 (a) O. Gidron, Y. Diskin-Posner and M. Bendikov, J. Am. Chem. Soc., 2010, 132, 2148-2149; (b) A. A. Jahnke, B. Djukic, T. M. McCormick, E. B. Domingo, C. Hellmann, Y. Lee and D. S. Seferos, J. Am. Chem. Soc., 2013, 135, 951-954; (c) C. R. B. Rhoden and G. Zeni, Org. Biomol. Chem., 2011, 9, 1301-1313.

6 (a) W. Kaim, A. Klein and M. Glöckle, Acc. Chem. Res., 2000, 33, 755-763; (b) S. F. Nelsen, Chem. - Eur. J., 2000, 6, 581-588; (c) K. D. Demadis, C. M. Hartshorn and T. J. Meyer, Chem. Rev., 2001, 101, 2655-2685; (d) D. M. D'Alessandro and F. R. Keene, Chem. Rev., 2006, 106, 2270-2298; (e) F. Pevny, E. Di Piazza, L. Norel, M. Drescher, R. F. Winter and S. Rigaut, Organometallics, 2010, 29, 5912-5918; $(f)$ J. Hankache and O. S. Wenger, Chem. Rev., 2011, 111, 5138-5178; $(g)$ D. Siebler, M. Linseis, T. Gasi, L. M. Carrella, 
R. F. Winter, C. Forster and K. Heinze, Chem. - Eur. J., 2011, 17, 4540-4551; (h) A. Heckmann and C. Lambert, Angew. Chem., Int. Ed., 2012, 51, 326-392; (i) P. J. Low, Coord. Chem. Rev., 2013, 257, 1507-1532.

7 (a) J. Guay, P. Kasai, A. Diaz, R. L. Wu, J. M. Tour and L. H. Dao, Chem. Mater., 1992, 4, 1097-1105; (b) P. Bäuerle, U. Segelbacher, A. Maier and M. Mehring, J. Am. Chem. Soc., 1993, 115, 10217-10223; (c) P. Bäuerle, U. Segelbacher, K. U. Gaudl, D. Huttenlocher and M. Mehring, Angew. Chem., Int. Ed., 1993, 32, 76-78; (d) Y. B. Zhu and M. O. Wolf, J. Am. Chem. Soc., 2000, 122, 10121-10125; (e) S. Le Stang, F. Paul and C. Lapinte, Organometallics, 2000, 19, 1035-1043; $(f)$ S. Fraysse, C. Coudret and J.-P. Launay, J. Am. Chem. Soc., 2003, 125, 5880-5888; $(g)$ D. Rohde, L. Dunsch, A. Tabet, H. Hartmann and J. Fabian, J. Phys. Chem. B, 2006, 110, 8223-8231; (h) J. C. Lacroix, K. I. Chane-Ching, F. Maquère and F. Maurel, J. Am. Chem. Soc., 2006, 128, 7264-7276; (i) P. Rapta, O. Zeika, D. Rohde, H. Hartmann and L. Dunsch, ChemPhysChem, 2006, 7, 863-870; $(j)$ S. A. Odom, K. Lancaster, L. Beverina, K. M. Lefler, N. J. Thompson, V. Coropceanu, J. L. Brédas, S. R. Marder and S. Barlow, Chem. - Eur. J., 2007, 13, 9637-9646; (k) G. Nöll, M. Avola, M. Lynch and J. Daub, J. Phys. Chem. C, 2007, 111, 3197-3204; (l) L. B. Gao, J. Kan, Y. Fan, L. Y. Zhang, S. H. Liu and Z. N. Chen, Inorg. Chem., 2007, 46, 5651-5664; $(m)$ A. W. Franz, L. N. Popa, F. Rominger and T. J. J. Müller, Org. Biomol. Chem., 2009, 7, 469-475; (n) J. Casado, S. R. Gonzalez, M. C. R. Delgado, M. M. Oliva, J. T. L. Navarrete, R. Caballero, P. de la Cruz and F. Langa, Chem. - Eur. J., 2009, 15, 2548-2559; (o) F. Zhang, G. Gotz, E. Mena-Osteritz, M. Weil, B. Sarkar, W. Kaim and P. Bäuerle, Chem. Sci., 2011, 2, 781-784; ( $p$ ) S. Barlow, C. Risko, S. A. Odom, S. J. Zheng, V. Coropceanu, L. Beverina, J. L. Brédas and S. R. Marder, J. Am. Chem. Soc., 2012, 134, 10146-10155; (q) J. M. Speck, R. Claus, A. Hildebrandt, T. Rüffer, E. Erasmus, L. van As, J. C. Swarts and H. Lang, Organometallics, 2012, 31, 6373-6380; (r) Y. P. Ou, J. L. Xia, J. Zhang, M. Xu, J. Yin, G. A. Yu and S. H. Liu, Chem. - Asian J., 2013,
8, 2023-2032; (s) L. G. Reuter, A. G. Bonn, A. C. Stückl, B. C. He, P. B. Pati, S. S. Zade and O. S. Wenger, J. Phys. Chem. A, 2012, 116, 7345-7352; $(t)$ M. Jenart, C. Niebel, J. Y. Balandier, J. Leroy, A. Mignolet, S. Stas, A. Van Vooren, J. Cornil and Y. H. Geerts, Tetrahedron, 2012, 68, 349-355.

8 (a) O. Gidron, Y. Diskin-Posner and M. Bendikov, Chem. - Eur. J., 2013, 19, 13140-13150; (b) D. M. D'Alessandro and F. R. Keene, Dalton Trans., 2004, 3950-3954.

9 (a) H. Nakanishi, S. Inoue and T. Otsubo, Mol. Cryst. Liq. Cryst., 1997, 296, 335-348; (b) S. Inoue, H. Nakanishi, K. Takimiya, Y. Aso and T. Otsubo, Synth. Met., 1997, 84, 341-342.

10 A. Hildebrandt and H. Lang, Organometallics, 2013, 32, 5640-5653.

11 (a) C. Lambert and G. Nöll, J. Am. Chem. Soc., 1999, 121, 8434-8442;

(b) C. Lambert, G. Nöll and J. Schelter, Nat. Mater., 2002, 1, 69-73;

(c) S. Barlow, C. Risko, S. J. Chung, N. M. Tucker, V. Coropceanu, S. C. Jones, Z. Levi, J. L. Brédas and S. R. Marder, J. Am. Chem. Soc., 2005, 127, 16900-16911; (d) J. Bonvoisin, J. P. Launay, M. Van der Auweraer and F. C. De Schryver, J. Phys. Chem., 1994, 98, 5052-5057; (e) D. Sun, S. V. Rosokha and J. K. Kochi, Angew. Chem., Int. Ed., 2005, 44, 5133-5136.

12 (a) C. Creutz, M. D. Newton and N. Sutin, J. Photochem. Photobiol., A, 1994, 82, 47-59; (b) R. J. Cave and M. D. Newton, Chem. Phys. Lett., 1996, 249, 15-19.

13 N. S. Hush, Prog. Inorg. Chem., 1967, 8, 391.

14 (a) S. F. Nelsen, A. E. Konradsson, M. N. Weaver and J. P. Telo, J. Am. Chem. Soc., 2003, 125, 12493-12501; (b) S. F. Nelsen, M. N. Weaver, J. I. Zink and J. P. Telo, J. Am. Chem. Soc., 2005, 127, 10611-10622; (c) K. Lancaster, S. A. Odom, S. C. Jones, S. Thayumanavan, S. R. Marder, J. L. Brédas, V. Coropceanu and S. Barlow, J. Am. Chem. Soc., 2009, 131, 1717-1723.

15 D. Miesel, A. Hildebrandt, M. Korb, P. J. Low and H. Lang, Organometallics, 2013, 32, 2993-3002.

16 C. Herrmann and J. Elmisz, Chem. Commun., 2013, 49, 10456-10458. 